\title{
The DTC with ANN of a DFIG Driven by a WECS
}

\author{
S.Bouhafna ${ }^{1}$, I.Toumi, ${ }^{2}$ S. Benaggoune ${ }^{3}$ B. Maghni ${ }^{4}$ \\ ${ }^{1,3}$ Faculty of technology, department of electrical engineering, University of Batna \\ street of mohamed el-hadi boukheloufe Batna -ALGERIA- \\ ${ }^{2,4}$ Faculty of technology, department of electrical engineering, University of Ouargla \\ street of ghardia,bp.511,3000 Ouargla -ALGERIA-
}

\begin{abstract}
This paper treats the modeling of a wind energy conversion system connected to the grid, which is composed of a horizontal axis wind turbine operating at variable wind speeds, a doubly- fed induction generator and two converters ( AC / DC and DC / AC) controlled by direct torque control (DTC) with application of neural networks. The results of simulations of the studied system are presented in the Matlab / Simulink environment.
\end{abstract}

Keywords:- Wind Turbine; DFIG; (DTC); artificial neural networks (ANN).

\section{INTRODUCTION}

To produce electrical energy using a wind energy conversion system (WECS), various control strategies should be developed in the literature The most widely used control techniques are the vector control (VC) and the direct control techniques. All these techniques aim to bring down the cost of electrical energy produced by the WECS and to converge the system for operating at unity power factor. For the rotor side converter (RSC), the VC strategy which guarantees high dynamics and static

Performance through an internal current control loops, has attracted much attention in the past few decades. However, the performance of the VC largely depends on the design of the current controllers and the tuning of their parameters. Direct Control eliminates the need for current regulators and specific modulations. DTC provides direct control of machine's torque and flux This approach achieves better steady state and transient torque control conditions, but it is penalized by the electromagnetic torque noises and the high switching frequency. The grid side converter (GSC) can also be controlled by VC technique. This method gives high static performances [2,3]. DTC strategy is one of the interesting control strategies, as an alternative to vector control for induction machines. The advantages of this technique are the fast dynamic response, the very low use of machine parameters and fairly simple control. The schematic diagram Fig. 1 of a system composed of mechanical and electrical parts with a control which has proposed $[4,7]$.

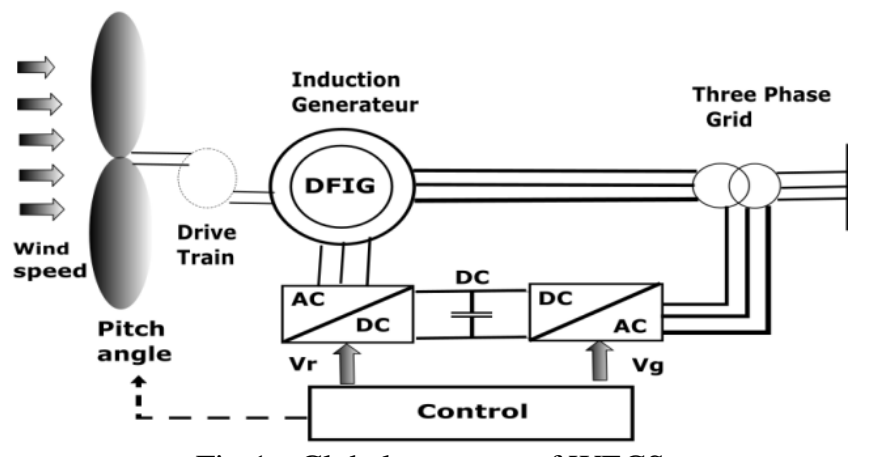

Fig 1:- Global structure of WECS

\section{THE CONVERSION SYSTEM MODELING}

$>$ Wind modeling:

The mathematical model of wind is given by [14]:

$V(t)=8+0.2 \sin (0.1047 . t)+2 \sin (0.2665 . t)+$

$0.2 \sin (3.6645 . t)$

\section{Turbine modeling:}

The mathematical model of power of wind turbine is given by : [7,4]:

$P_{a e r}=\frac{1}{2} \rho \cdot R^{2} \cdot V^{3}$.

The equations ( 3 and 4 ) given respectively the aerodynamic power and torque of wind turbine [1,9] :

$P_{a e r}=\frac{1}{2} \rho \cdot R^{2} \cdot V^{3} \cdot C_{p}(\lambda, \beta)$

(3)

$T_{\text {aer }}=\frac{P_{a e r}}{\Omega_{t}}=\frac{1}{2} \rho \cdot \pi R^{2} \cdot V^{3} \cdot C_{p}(\lambda, \beta) \cdot \frac{1}{\Omega_{t}}$

Where: $\quad \rho:$ is $a$ air density power coefficient

$R: i$ s $a$ radius of the turbine

$V$ :is $a$ wind speed:

$\lambda: i s$ a the tip speed ratio

$\beta$ : is a blade pitch angle

The power coefficient $C_{p}$ of the wind turbine is given as:

$$
\begin{aligned}
& C_{p}(\lambda, \beta)=0.5176\left(\frac{116}{\lambda_{i}}-0.4 \beta .-5\right) e^{\frac{21}{\lambda_{i}}}+0.0068 \lambda \\
& \quad \frac{1}{\lambda_{i}}=\frac{1}{\lambda+0.08 \beta}-\frac{0.035}{\beta^{3}+1} \\
& \lambda=\frac{R \Omega_{t}}{V}
\end{aligned}
$$


Where $\Omega_{t}$ is the wind turbine speed. The limit of BETZ:

$$
C_{p}(\lambda, \beta)=\frac{P_{m}}{P_{\text {wind }}}=\frac{16}{27}=0.593
$$

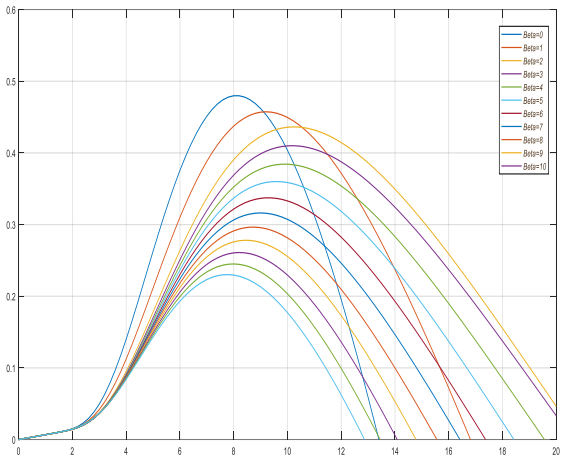

Fig 2:- The Coefficient power $\mathrm{Cp}=\mathrm{f}(\lambda)$.

The $C_{p-\max }$ as depicted in Figure 2 .We have to maintain the tip speed ratio at its optimal value, $C_{p}=0.48$ and $\beta$ should be equal to $0 .[10,11]$ Fig. 2 .

The gearbox is given by the two following equations:

$T_{m}=\frac{T_{a e r}}{G}$

$\Omega_{t}=\frac{\Omega_{m}}{G}$

Where: $T_{m}$ generator torque

$T_{\text {aer }}$ Turbine torque

The relationship between torque and speed is written:

$T_{g}-T_{e m}=J \frac{d \Omega_{m e c}}{d t}+f . \Omega_{m e c}$

Where: $J$ : the moment of inertia

$f:$ the friction coefficient

\section{Modeling of the DFIG:}

the stator and rotor voltage equations of the DFIG are written: $[4,5,6,8,12]$ :

$$
\begin{gathered}
\left\{\begin{array}{l}
V_{d s}=R_{s} \cdot I_{d s}+\frac{d \varphi_{d s}}{d t}-\omega_{s} \cdot \varphi_{q s} \\
V_{q s}=R_{s} \cdot I_{q s}+\frac{d \varphi_{q s}}{d t}+\omega_{s} \cdot \varphi_{d s} \\
V_{d r}=R_{r} \cdot I_{d s}+\frac{d \varphi_{d r}}{d t}-\omega_{r} \cdot \varphi_{q r} \\
V_{q r}=R_{r} \cdot I_{d s}+\frac{d \varphi_{q r}}{d t}+\omega_{r} \cdot \varphi_{d r}
\end{array}\right. \\
\left\{\begin{array}{l}
\varphi_{d s}=L_{s} \cdot I_{d s}+M I_{d r} \\
\varphi_{q s}=L_{s} \cdot I_{q s}+M I_{q r} \\
\varphi_{d r}=L_{r} \cdot I_{d r}+M I_{d s} \\
\varphi_{q r}=L_{r} \cdot I_{q r}+M I_{q s}
\end{array}\right.
\end{gathered}
$$

The torque $T_{e m}$ can be written as follows [6]:

$T_{e m}=-\frac{3}{2} p \frac{M}{L_{r}}\left(\varphi_{d s} \cdot I_{q r}-\varphi_{q s} I_{d r}\right)$
Generator active and reactive powers at the stator side are given by the expressions:

$$
\begin{aligned}
& P_{s}=\frac{3}{2}\left(V_{d s} \cdot I_{d s}+V_{q s} \cdot I_{q s}\right) \\
& Q_{s}=\frac{3}{2}\left(V_{q s} \cdot I_{d s}-V_{d s} \cdot I_{q s}\right)
\end{aligned}
$$

\section{DTC PRINCILES FOR DFIG}

Figure 3 shows the DTC diagram of the DFIG. in the stator is directly connected to the grid and the rotor is powered by two converters which also connected to the grid. The main objective of the DTC is to directly control the rotor flux and the electromagnetic torque of the DFIG by choosing the best voltage vector $[1,6,10,13]$

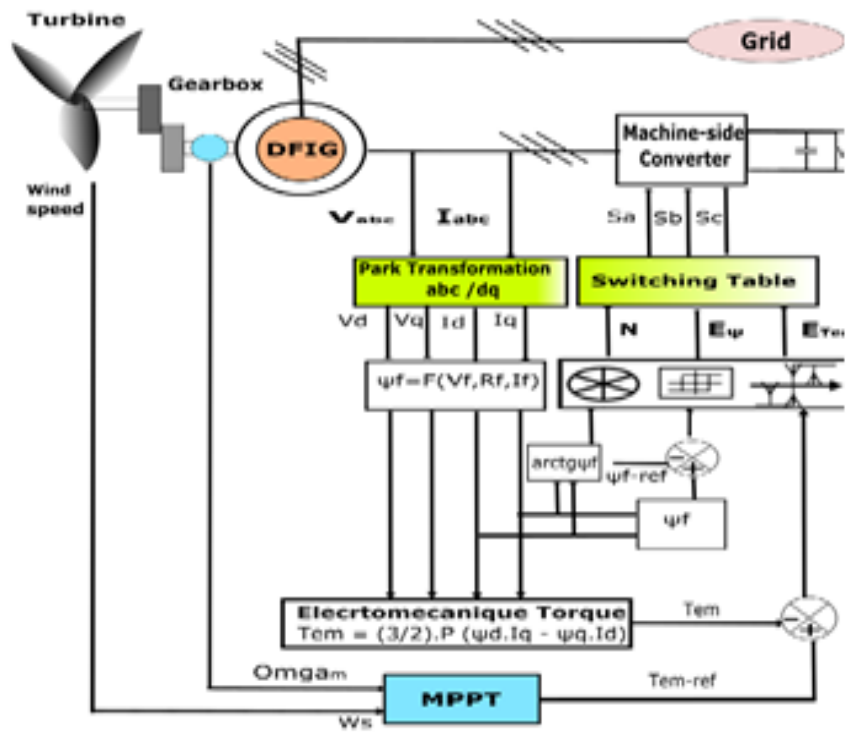

Fig 3:- The diagram DTC of the DFIG

As shown in Fig. 4, the position of the rotor flux is divided into six sectors. There are also 8 voltage vectors which correspond to possible inverter states. These vectors are shown in Fig. 3. There are also six active vectors V1, $\mathrm{V} 2, \ldots, \mathrm{V} 6$ and two zero vectors V0 and V7. $[1,10]$

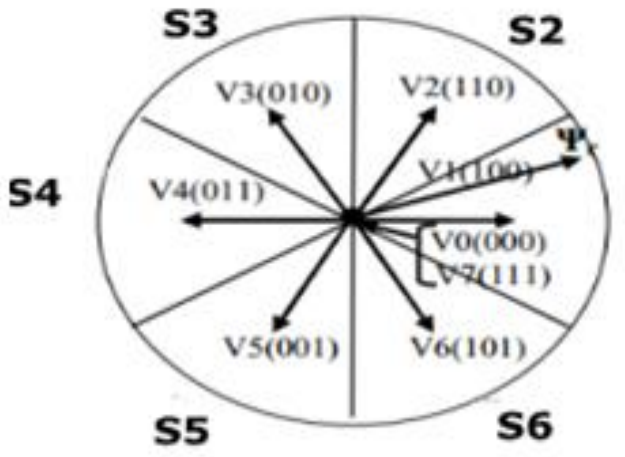

S1

Fig 4:- Detection of vector voltage 


\begin{tabular}{|l|c|c|c|c|c|c|c|}
\hline \multicolumn{2}{|c|}{ Sector } & 1 & 2 & 3 & 4 & 5 & 6 \\
\hline$E \Psi$ & $E_{\text {Tem }}$ & & & & & & \\
\hline \multirow{3}{*}{$E \Psi=1$} & $E_{\text {Tem }}=1$ & $\mathrm{~V}_{2}$ & $\mathrm{~V}_{3}$ & $\mathrm{~V}_{4}$ & $\mathrm{~V}_{5}$ & $\mathrm{~V}_{6}$ & $\mathrm{~V}_{1}$ \\
\cline { 2 - 8 } & $E_{\text {Tem }}=0$ & $\mathrm{~V}_{7}$ & $\mathrm{~V}_{0}$ & $\mathrm{~V}_{7}$ & $\mathrm{~V}_{0}$ & $\mathrm{~V}_{7}$ & $\mathrm{~V}_{0}$ \\
\cline { 2 - 7 } & $E_{\text {Tem }}=-1$ & $\mathrm{~V}_{6}$ & $\mathrm{~V}_{1}$ & $\mathrm{~V}_{2}$ & $\mathrm{~V}_{3}$ & $\mathrm{~V}_{4}$ & $\mathrm{~V}_{5}$ \\
\hline \multirow{3}{*}{$E \Psi=0$} & $E_{\text {Tem }}=1$ & $\mathrm{~V}_{3}$ & $\mathrm{~V}_{4}$ & $\mathrm{~V}_{5}$ & $\mathrm{~V}_{6}$ & $\mathrm{~V}_{1}$ & $\mathrm{~V}_{2}$ \\
\cline { 2 - 8 } & $E_{\text {Tem }}=0$ & $\mathrm{~V}_{0}$ & $\mathrm{~V}_{7}$ & $\mathrm{~V}_{0}$ & $\mathrm{~V}_{7}$ & $\mathrm{~V}_{0}$ & $\mathrm{~V}_{7}$ \\
\cline { 2 - 8 } & $E_{\mathrm{Tem}}=-1$ & $\mathrm{~V}_{5}$ & $\mathrm{~V}_{0}$ & $\mathrm{~V}_{1}$ & $\mathrm{~V}_{2}$ & $\mathrm{~V}_{3}$ & $\mathrm{~V}_{4}$ \\
\hline
\end{tabular}

Table 1: Switching states

The classic DTC has drawbacks namely: the harmonics of the currents in the two regimes also a variable switching frequency and the ripples of the torque and the flux. so we proposed this command based on neural networks where the switching table is replaced by a neural controller see figure 5 [4]

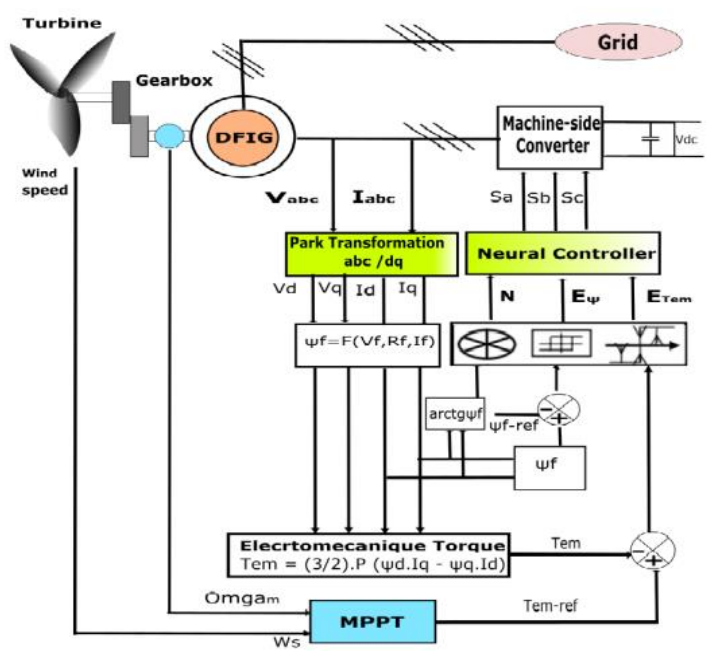

Fig 5:- DTC Neural Networks Controller scheme.

Rotor flux linkage estimation

$\widehat{\psi_{r}}=\int_{0}^{t}\left(V_{r}-R_{r} i_{r}\right) d t$

The $\alpha$ and $\beta$ estimates components of the $\psi_{r}$ vector obtained by :

$\widehat{\psi_{r \alpha}}=\int_{0}^{t}\left(V_{r \alpha}-R_{r} i_{r \alpha}\right) d t$

$\widehat{\psi_{r \beta}}=\int_{0}^{t}\left(V_{r \beta}-R_{r \beta} i_{r \beta}\right) d t$

The module of the rotor flux is given by:

$\psi_{r}=\sqrt{\psi_{r \alpha}^{2}+\psi_{r \beta}^{2}}$

The phase of the rotor flux is given by:

$\theta_{\mathrm{r}}=\operatorname{arctg} \frac{\psi_{\mathrm{r} \beta}}{\psi_{\mathrm{r} \alpha}}$

The torque of DFIG can be represented as a function of the angle $\delta$ between the stator and the rotor fluxes space vectors as follows $[3,6]$ :

$T_{e m}=\frac{3}{2} P \frac{M}{\sigma L_{r} L_{s}}\left|\psi_{r}\right| \cdot\left|\psi_{s}\right| \sin \delta$

Where $\sigma=1-\frac{\mathrm{M}^{2}}{\mathrm{~L}_{\mathrm{r}} \mathrm{L}_{\mathrm{s}}}$ is the leakage coefficient

\section{THE NEURAL CONTROLLER}

To generate a neural controller by Matlab / simulink, 30 neurons were chosen in the hidden layers and 3 in the output layers with activation functions of the $\langle\tan s i g\rangle$ and <purelin> type respectively. The update of the weights and biases of this network is carried out by a retropropagation algorithm called the Levenberg-Marquardt (LM) algorithm. $[5,6]$.

$y_{i}=f\left[\sum_{j=1}^{n i} W_{i j} . X_{j}-b_{i}\right]$

The perceptions multi-layer (Figure 06) is a network comprising L layers, each neuron of a layer being completely connected to the neurons of the following layer. Each neuron $k$ is a generalized linear automat whose function of activation is $f_{k}$.

ANN Program Using MATLAB/Simulink:

$\mathrm{p}=\left[\begin{array}{lllllllllllllllllllllllllllll}1 & 1 & 1 & 1 & 1 & 1 & 1 & 1 & 1 & 1 & 1 & 1 & 1 & 1 & 1 & 1 & 1 & 1 & 1 & 1 & 1 & 1 & 1 & 1 & 1 & 1 & 1 & 1 & 1\end{array}\right.$ $\left.\begin{array}{lllllll}1 & 1 & 1 & 1 & 1 & 1\end{array}\right]$

$\% \mathrm{p}=\mathrm{p}^{\prime}$;

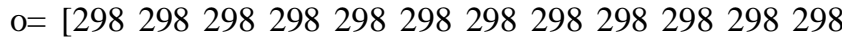

298298298298298298298298298298298298298

298298298298298298298298298298 298];

net.numInputs $=1$;

net.numLayers $=4$;

net $=$ newff([0360],[36,1], \{'tansig','purelin' $\},$ 'traingdm');

net.trainparam. $1 \mathrm{r}=0.002$;

net.trainparam.epochs $=5000$;

net.trainparam.goal $=0$;

net.trainParam.min_grad=1e-40;

net=train (net,p,o);

Gensim (net,-1)

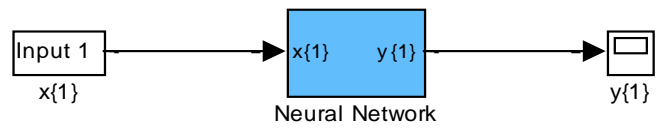

Fig 6:- Structure of ANN.

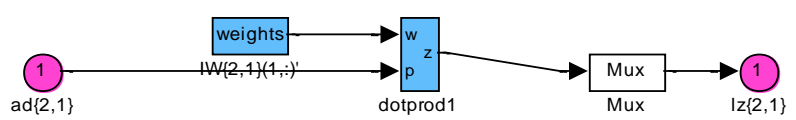

Fig 7:- Structure of layer 1.

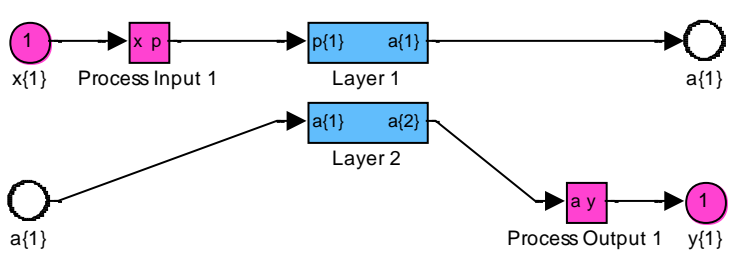

Fig 8:- Structure of layer 2. 


\section{SIMULATIONS RESULTS}

To show the behavior of the DFIG induction generator, connected to the network through a bidirectional converter, we have introduced a variable wind profile, from which, The reference value of the torque is deduced from the regulation of the speed of the wind turbine according to the wind speed and using a PI corrector.

The results of simulations showed that the flux trajectory is circular (Fig. 9), the stator currents are sinusoidal (Fig. 10) and the estimated speed follows the reference speed (Fig. 13).

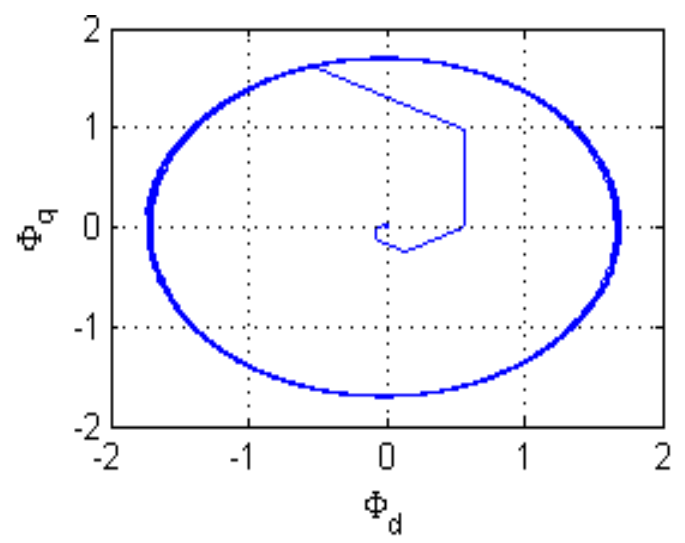

Fig 9:- The trajectory of flux

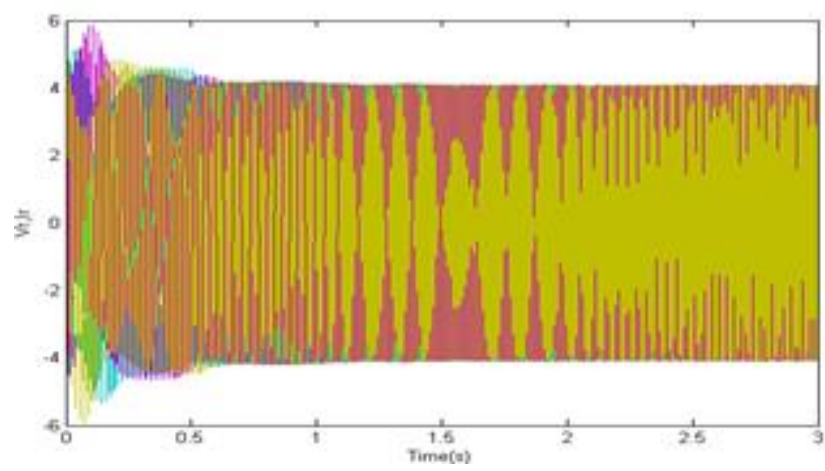

Fig 10:- The current and voltage of roto

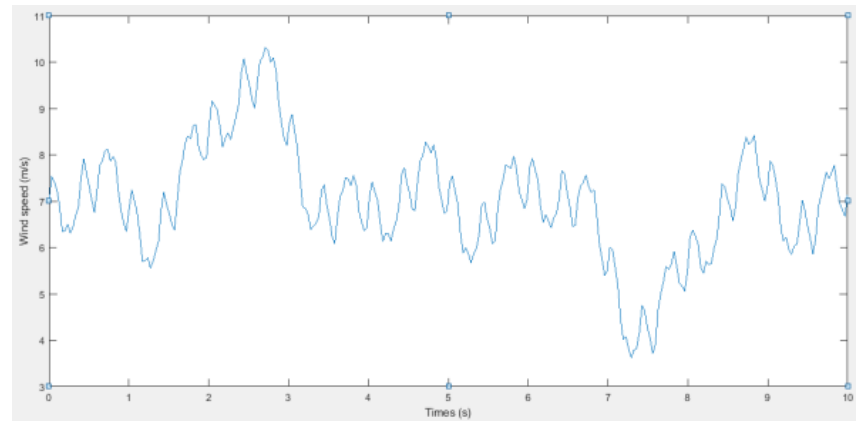

Fig 11:- The wind speed

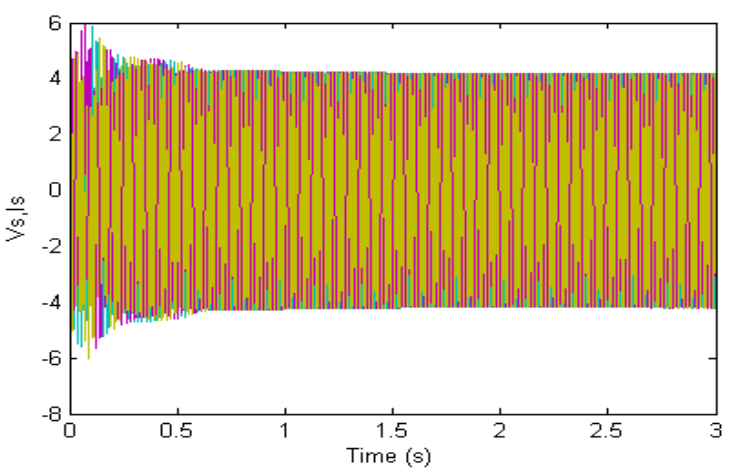

Fig 12:- The current and voltage of the stator

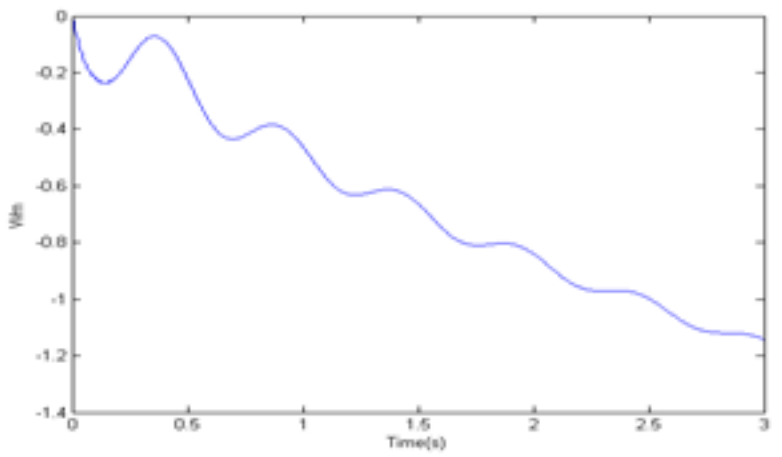

Fig 13:- The speed

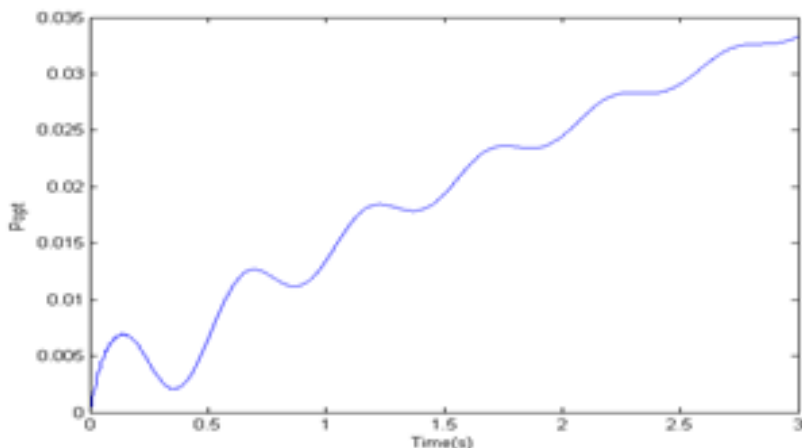

Fig 14:- The power

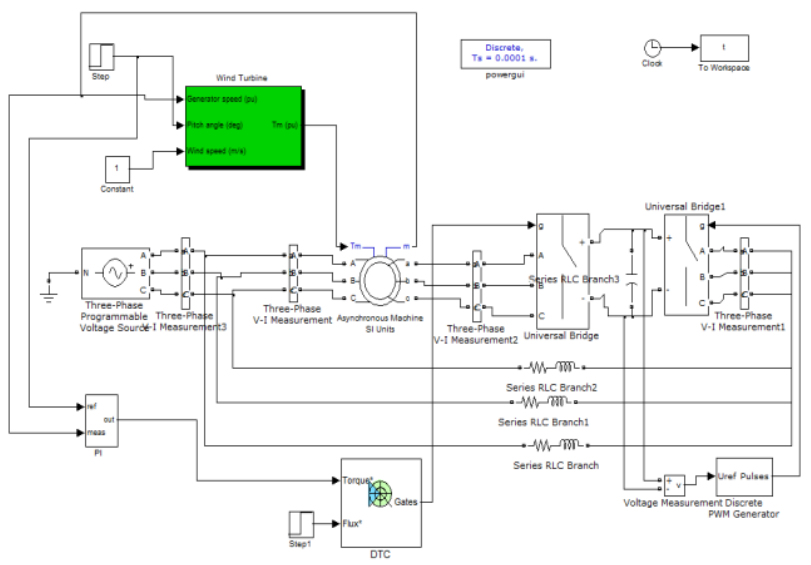

Fig 15:- Structure of the DFIG with DTC 


\section{CONCLUSION}

The application of DTC to the DFIG has shown that this technique responds perfectly to the variations undergone during the simulation vis-à-vis the conditions applied, which explains why the machine chosen is good performance and its simplicity, on the other hand this control technique presents drawbacks, to overcome its drawbacks, we have proposed a modified DTC technique, by the application of artificial intelligence techniques (neural network). The control of the speed of the DFIG we proposed an algorithm based on artificial neural networks (ANN) with reference model. The results of simulation under Simulink / Matlab, of the proposed block diagram have given proof of the efficiency of the proposed control techniques.

\section{Appendix}

System settings

Rated power: $P n=1.5 \mathrm{~kW}$

Rated voltage: $v / U=398 / 660 \mathrm{~V}-50 \mathrm{~Hz}$

The nominal speed: $\Omega n=1440 \mathrm{tr} / \mathrm{min}$.

Number of pole pairs: $P=2$

The parameters of the wind turbine used:

Number of blades: $N p=3$

Diameter of a blade: $R T=35.25 m$

Inertia: $J=1000 \mathrm{Kg} . \mathrm{m} 2$

Number of blades: $N p=3$

Stator resistance: $\mathrm{Rs}=0.0146 \Omega$

Rotor resistance: $R \mathrm{r}=0.0238 \Omega$

Stator inductance: $L s=0.0306 H$

Rotor inductance: $\mathrm{Lr}=0.0306 \mathrm{H}$

Mutual inductance: $L \mathrm{~m}=0.0299 \mathrm{H}$

Mechanical constants:

Moment Inertia: $J=1000 \mathrm{Kg} \cdot \mathrm{m} 2$

Coefficient of friction: $f=0.001 N . m . S / \mathrm{rad}$

Optimal tip speed ratio: $\lambda_{o p t}=8$

Gearbox coefficient: $\mathrm{G}=55.747$

Cut-in wind speed: $V_{\min }=3 \mathrm{~m} / \mathrm{s}$

Cutoff wind speed: $V_{\text {max }}=25 \mathrm{~m} / \mathrm{s}$

\section{REFERENCES}

[1]. Arnalte, S., Burgos, J. C., \& Rodriguez-Amenedo, J. L. (2002). Direct torque control of a doubly-fed induction generator for variable speed wind turbines. Electric power components and systems, 30(2), 199-216.

[2]. Alaya, J. B., Khedher, A., \& Mimouni, M. F. (2011). DTC, DPC and nonlinear vector control strategies applied to the dfig operated at variable speed. Journal of Electrical Engineering JEE, 6(11), 744-753.

[3]. Bakouri, A., Mahmoudi, H., \& Abbou, A. (2016). Intelligent control for doubly fed induction generator connected to the electrical network. International Journal of Power Electronics and Drive Systems, 7(3), 688.
[4]. Bakouri, A., Mahmoudi, H., Abbou, A., \& Moutchou, M. (2015, October). Optimizing the wind power capture by using DTC technique based on artificial neural network for a DFIG variable speed wind turbine. In 2015 10th International Conference on Intelligent Systems: Theories and Applications (SITA) (pp. 1-7). IEEE.

[5]. Benbouhenni, H., \& Boudjema, Z. (2018, November). Two-level DTC based on ANN controller of DFIG using 7-level hysteresis command to reduce flux ripple comparing with traditional command. In 2018 International Conference on Applied Smart Systems (ICASS) (pp. 1-8). IEEE.

[6]. Djeriri, Y., Meroufel, A., \& Massoum, A. (2014). Artificial neural network based direct torque control of doubly fed induction generator. Journal of electrical Engineering, 14.

[7]. Elkhadiri, S., Elmenzhi, P. L., Haddi, P. A., \& Lyhyaoui, P. A. (2017). Control of a doubly-fed induction generator for wind energy by ANN. In International conference on automation, control engineering and computer science (ACECS) proceedings of engineering and technology-PET (pp. 96-101).

[8]. Elazzaoui, M. (2015). Modeling and control of a wind system based doubly fed induction generator: Optimization of the power produced. Journal of Electrical \& Electronics, 4(1), 1.

[9]. Hassan, A. A., El-Sawy, A. M., \& Kamel, O. M. (2013). Direct torque control of a doubly fed induction generator driven by a variable speed wind turbine. Journal of Engineering Sciences, Assiut University, 41(1), 199-216.

[10]. Kadri, A., Marzougui, H., Omrani, K., \& Bacha, F. (2017, December). DTC of doubly fed induction generator for wind power system based on rotor flux estimation. In 5th international conference on control engineering \& information technology (CEIT-2017), Proceeding of engineering and technology, Sousse, Tunisia (pp. 17-19).

[11]. Khajuria, S., \& Kaur, J. (2012). Implementation of pitch control of wind turbine using Simulink (Matlab). International Journal of Advanced Research in Computer Engineering \& Technology, 1(4), 196200.

[12]. Moualdia, A., Boudana, D., Bouchhida, O., \& Wira, P. (2016, November). Direct torque control based multilevel inverter and artificial neural networks of wind energy conversion system. In 2016 8th International Conference on Modelling, Identification and Control (ICMIC) (pp. 49-54). IEEE.

[13]. Naveen, G., Sarvesh, P. K. S., \& Krishna, B. R. (2013). DTC control strategy for doubly fed induction machine. International journal of Engineering and advanced Technology (IJEAT), 3(1), 92-95.

[14]. Moulay, F., Habbatti, A., \& Hamdaoui, H. (2019). Application and Control of a Doubly Fed Induction Machine Integrated in Wind Energy System. Journal homepage: http://iieta. org/journals/i2m, 18(3), 257265. 
NOMENCLATURE

\begin{tabular}{|c|c|}
\hline WECS & Wind Energy Conversion System \\
\hline DFIG & Doubly Fed Induction Generator \\
\hline $\mathrm{V}_{\mathrm{ds}} \mathrm{V}_{\mathrm{qs}} \mathrm{V}_{\mathrm{dr}} ; \mathrm{V}_{\mathrm{qr}}$ & $\begin{array}{c}\text { Stator and Rotor Voltage } \\
\text { components in the d-q reference } \\
\text { frame }\end{array}$ \\
\hline$\varphi_{d s}, \varphi_{q s}, \varphi_{d r} \varphi_{q r}$ & $\begin{array}{l}\text { Stator and Rotor flux components in } \\
\text { the d-q reference frame }\end{array}$ \\
\hline$I_{d s}, I_{q s}, I_{d r}, I_{q r}$ & $\begin{array}{c}\text { Stator and Rotor currents } \\
\text { components in the d-q reference } \\
\text { frame }\end{array}$ \\
\hline$\omega_{s}, \omega_{r}$ & Stator frequency, rotor rotating speed \\
\hline$R_{s}, R_{r}$ & Stator- Rotor resistances \\
\hline$L_{s}, L_{r}$ & Stator and Rotor inductance \\
\hline$L_{m}$ & Mutual inductance \\
\hline$P_{S}, Q_{s}$ & Active and Reactive stator power \\
\hline $\mathrm{P}$ & Number of pole pairs \\
\hline$T_{e m}$ & Electromagnetic torque \\
\hline$P_{a e r}$ & Mechanical turbine power \\
\hline $\mathrm{S}$ & Section of blade \\
\hline$C_{p}$ & The aerodynamic coefficient power \\
\hline $\mathrm{R}$ & Radius of the wind turbine \\
\hline $\mathrm{F}$ & Friction coefficient \\
\hline $\mathrm{J}$ & Inertia moment \\
\hline$\Omega_{t}$ & Wind turbine speed \\
\hline$\lambda$ & Tip speed ratio \\
\hline$\beta$ & Blade pitch angle \\
\hline$\rho$ & Air density \\
\hline V & Wind speed \\
\hline
\end{tabular}

Table 2 